\title{
A Transformation of Oral English Teaching Method in the Network Environment
}

\author{
Yanwei Gong (iD \\ Xuzhou Vocational College of Bioengineering, Xuzhou 221006, China \\ Correspondence should be addressed to Yanwei Gong; gyw@xzsw.net
}

Received 1 October 2021; Revised 9 December 2021; Accepted 21 December 2021; Published 23 February 2022

Academic Editor: Jamil Hussain

Copyright (C) 2022 Yanwei Gong. This is an open access article distributed under the Creative Commons Attribution License, which permits unrestricted use, distribution, and reproduction in any medium, provided the original work is properly cited.

In order to effectually improve the application effect of the existing oral English teaching methods, this paper studies the conversion of effective oral English teaching methods under the network environment, aiming at the application problems, such as the flexibility of the current education platform. We build an effective oral English teaching platform which is comprised of oral English perception processing module, oral English pronunciation acquisition program module, oral English pronunciation preprocessing module, and oral English pronunciation error detection modeling module. We establish the information technology teaching objectives of the effective oral English teaching model on this basis. This research work is focused on the study of the output driven input-facilitated college oral English teaching model in oral English classroom. It is performed to realize the transformation of effective oral English teaching methods under the network environment. The experimental results show that the transformation effect of the effective teaching method of oral English, under the designed network environment, is better as compared to the existing work. The error detection rate in the proposed methodology reaches up to $98.6 \%$, which is significantly higher than the results obtained by researchers in their existing work. The proposed method has obvious application advantages.

\section{Introduction}

College English teaching aims to cultivate students' ability to comprehensively apply English, with special emphasis on the cultivation of oral English ability [1]. There are two different levels of oral English proficiency, which are general requirements and higher requirements, respectively. In this study, the requirements of each level of English are explained in detail. The general requirements point out that the pronunciation and intonation of students should be basically correct and able to make concise narration or speech in English for the topics used in daily life. The higher requirement indicates that students should be able to use English in a general conversation and be able to express their opinions and positions on this basis. Higher requirements require students to be able to accurately discuss general topics or relatively strong professional topics at a higher level. Higher requirements even point out that students can speak and communicate in international occasions. Through the analysis of the two levels in the requirements, more emphasis is given to English listening and speaking skills are even more than to English reading and writing skills. The meaning of network environment has two layers. One is that the Internet has penetrated into all aspects of social life and brought great changes to students' oral English learning. The second is the wide application of big data, with the increase of various types of teaching terminal equipment and mobile and nonmobile terminal teaching equipment; the data generated will be more and more. For English teachers, oral English teachers should timely change their teaching concepts [2]. Oral English teaching should not be satisfied with the traditional oral English teaching, which only serves for the superficial understanding of daily communication, rather than the mechanical memory of sentence patterns. Instead, oral English should be based on life and close to the living situation of students, gradually developing students' ability to use English thinking and improving their comprehensive expression ability [3]. Oral English can be integrated into life, applied to career, and serve the language needs of civilization [4]. Students should not be satisfied 
with the existing level of communication, stagnant, but also should continue to increase the input of oral English learning, using a variety of ways and methods to effectively reach the higher requirements of the standard.

\section{Related Work}

With the change of effective teaching methods of spoken English, many scholars have done a lot of research. Reference [5] puts forward the research of college oral English teaching under the perspective of adaptation theory. For a long time, oral English has been a difficult point in English teaching. Adaptation theory can not only make oral communication pay more attention to the change of context, the mode of communication more flexible, and the goal clearer and more direct but also make both sides adjust the rhythm of dialogue. From the perspective of adaptation theory, college oral English teaching should construct an adaptive learning environment. It should create a real oral English communication context and use task-based teaching method to carry out oral English teaching and explore the extracurricular position of oral English teaching. In the research study [6] based on the theory of constructivism and autonomy learning, the reasons for the weak awareness of autonomy in oral English learning and the disadvantages of traditional oral English teaching are analyzed. They analyze how to integrate the Internet with oral English learning, explore the cultivation of oral English autonomous learning in the environment of "Internet Plus," and realize the networked, digitalized, and intelligent learning environment, which is conducive to the cultivation and promotion of oral English autonomous learning ability of college students and the effective improvement of oral English communication skills. Reference [7] suggests constructing an English teaching environment by the integration of IT and all kinds of educational resources. They analyze English teaching putting forward the idea of teaching by using virtual reality technology in the classroom. Similarly, many other researchers focus their studies $[8,9]$ on the use of virtual reality and augmented reality in oral English teaching.

Although the above methods have made some progress, the overall flexibility is poor, and the course interaction including exchange learning and community visit cannot be carried out at any time. Students can learn spoken English from the interaction between students during spoken English sessions. This stimulates students to participate in spoken English. To get an excel level in spoken English, initiative and enthusiasm, which are the key factors, can play a vital role. An effective distance education teaching and collaboration can greatly improve learning efficiency and meet the requirements of oral English learning.

\section{Effective Oral English Teaching Platform under the Network Environment}

The establishment of an effective oral English teaching platform is the premise and basis for the transformation of effective teaching methods, and different modules are the key to operation of the design platform [10]. The design of effective oral English teaching platform mainly includes oral English perception processing module, oral English pronunciation acquisition program module, oral English pronunciation preprocessing module, and oral English pronunciation error detection modeling module. The specific design process is as follows.

3.1. Oral English Perception Processing Module. In the network environment, based on the needs of oral English pronunciation calibration, the speech sensing sensor selection unit and oral English pronunciation processor selection unit are designed. The specific design process is as follows.

3.1.1. Spoken English Speech Sensing Sensor Selection Unit. Oral English speech sensing sensor undertakes the task of collecting oral English pronunciation information and provides sufficient data support for the effective teaching method of subsequent oral English pronunciation calibration $[8,9]$. In the network environment, the spoken English speech sensing sensor used today realizes speech recognition through diodes. It can convert spoken English pronunciation into corresponding digital signals, which is convenient for computer recognition.

According to the requirements of the design platform, the sound sensor is selected as the speech sensing sensor of the effective oral English teaching platform. In the network environment, the sound sensor is essentially equivalent to a microphone, in which a capacitive electret microphone is placed. When spoken English is pronounced, the electret film will vibrate, and the capacitance and voltage will change accordingly, which will be transmitted to the computer through the A/D conversion circuit.

In the network environment, the performance parameters of sound sensor are shown in Table 1.

\subsubsection{Selection Unit of the Oral English Pronunciation} Processor. Oral English pronunciation processor needs to have control function and high-speed operation function and also needs to process oral English pronunciation in real time, so as to improve the error detection accuracy and calibration efficiency of oral English pronunciation [11]. According to the design requirements of the system, DSP chip is selected as the processor of the system, which can process the digital signal of oral English pronunciation output by the sound sensor.

The DSP chip adopts Harvard structure, under which the internal program and data of the chip are independent of each other. At the same time, a special hardware multiplier is used to output special instructions to provide support for the digital information processing of the system. The performance parameters of DSP chip are shown in Table 2.

3.2. Oral English Pronunciation Acquisition Program Module. Oral English pronunciation acquisition is an important program to design an effective oral English teaching 
TABle 1: Performance parameters of the sound sensor.

\begin{tabular}{lcc}
\hline Parameter & Setup & Remarks \\
\hline Measuring sound intensity & $45-120 \mathrm{~dB}$ & Gear 1 \\
Measurement waveform & $0-5 \mathrm{~V}$ & Gear 12 \\
Resolving power & $1 \mathrm{~Hz}$ & - \\
Accuracy & $\pm 1 \%$ & - \\
Sampling frequency & 10000 times/s & Minimum value \\
Output current & $4-20 \mathrm{~mA}$ & ZS series \\
Calibration times & 0 times & Software automatic zero adjustment \\
\hline
\end{tabular}

TABle 2: Performance parameters of the DSP chip.

\begin{tabular}{lcc}
\hline Parameter & Setup & Remarks \\
\hline Fixed point & 16 bits/32 bits & - \\
Instruction cycle & $200 \mathrm{~ns}$ & Maximum \\
Frequency & $100 \mathrm{MHz}$ & - \\
Mac time & One instruction cycle & Time of one multiplication + one addition \\
FFT execution time & $450 \mathrm{~ns}$ & Time to run an $N$ point FFT program \\
Power supply & PT64xx & - \\
Flash & AM29LV400 & - \\
Converter & A/D or D/A & - \\
Instructions executed per second & $100 \mathrm{mips}$ & Unit: millions \\
\hline
\end{tabular}

platform. The digital signals of oral English pronunciation are collected through the speech sensing sensor in the oral English perception processing module to prepare for the final automatic calibration of oral English pronunciation.

The process starts with determining whether the user opts to install the acquisition device and the acquisition parameters are initialized if the device is installed. The buffer information is copied and the parameters for the endpoint detection are calculated to turn on the endpoints. In the next step, if the detection is over, the information is passed to the callback function. Figure 1 illustrates the acquisition procedure of oral English pronunciation.

3.3. Oral English Pronunciation Preprocessing Module. Based on the oral English pronunciation digital signal collected by the above oral English pronunciation acquisition module, preemphasis, frame, and window processing are carried out [12], and the oral English pronunciation features are extracted to provide accurate signal support for the next module.

The first mock exam of the speech signal is caused by the influence of the nose and glottis, which will cause some attenuation of the high frequency signal, which will bring some difficulties to the pronunciation error detection. Therefore, this study preemphasizes the pronunciation digital signal through the digital filter, and the expression is

$$
F(H)=\alpha \times G(n) .
$$

In formula (1), $\alpha$ represents the pre-weighting coefficient, $G(n)$ represents the digital filter expression, and the value range is $[0.9,1.0]$. The relationship expression between the input signal and the output signal of the preemphasis network is

$$
H(m)=D(n)-\alpha \times \widetilde{D}(n) .
$$

In formula (2), $D(n)$ and $\widetilde{D}(n)$ represent input signal and output signal, respectively.

In fact, the pronunciation digital signal is not stable, which is mainly caused by the movement of pronunciation organs. The physical movement of the pronunciation organ is relatively slow, so this study finds that the pronunciation digital signal conforms to the characteristics of short-term stability. On this basis, the input signal is processed by frame windowing method to obtain a new time-dependent signal sequence and eliminate the nonstationarity of the pronunciation signal.

The collected original pronunciation digital signal is recorded as $k(c)$ and can be divided into multiple short segments by multiplying it by the window function. It should be noted that the amplitude of the window function is not fixed, and the original pronunciation digital signal needs to be weighted.

The short segment processing formula of the original spoken English pronunciation signal is

$$
R_{d}=\sum_{m=-\infty}^{\infty} J[k(c)] w(n-m) .
$$

In formula (3), $R_{d}$ represents the time series after framing and windowing, $J$ represents a linear transformation, and $w(n-m)$ represents window function. According to the pronunciation signal processing requirements of the design platform, Hanning window is selected for windowing the signal, and the expression is

$$
P_{f}= \begin{cases}0.5[1-\cos (2 \pi n /(N-1))], & 0 \leq n \leq N-1, \\ 0, & \text { other. }\end{cases}
$$




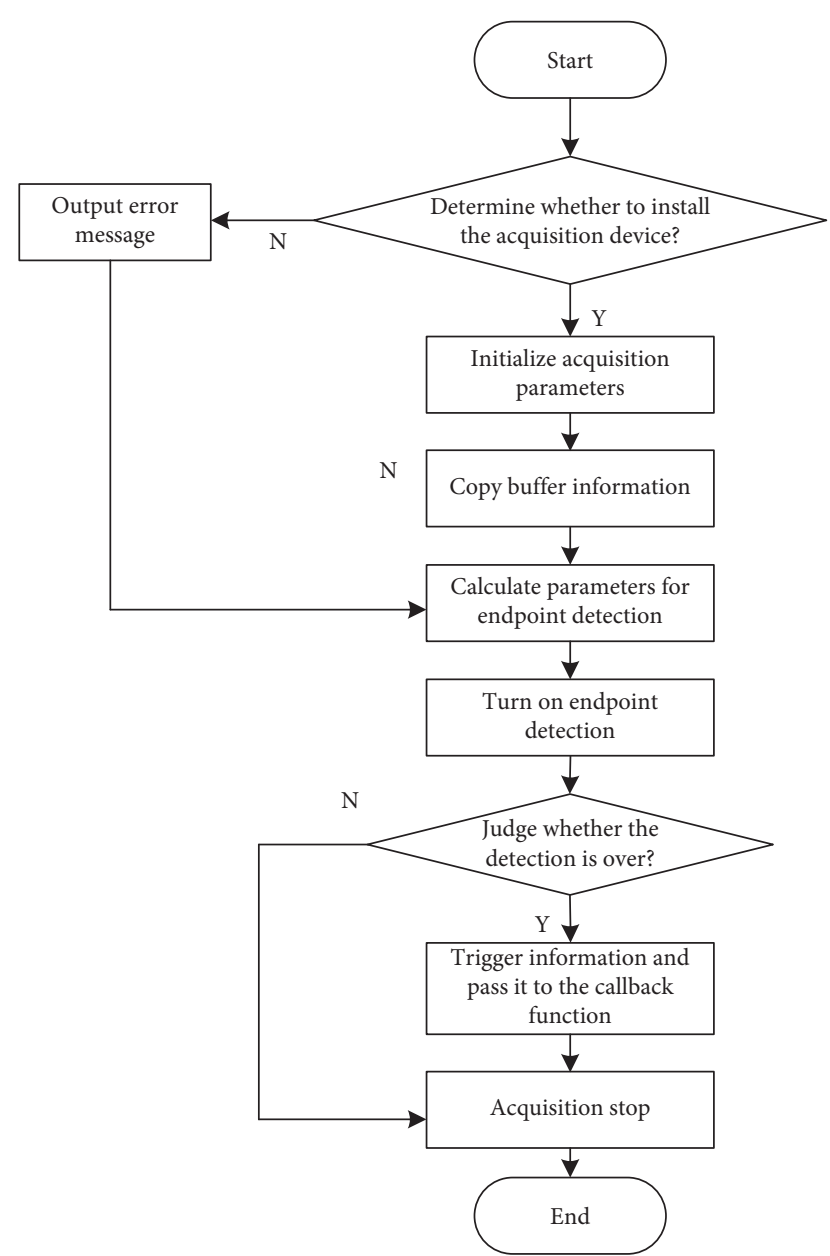

Figure 1: Flow chart of oral English pronunciation collection.

Based on the spoken English pronunciation signal processed by preemphasis, frame division, and windowing $[11,13]$, the Mel cepstrum coefficient (MFCC) of the signal is extracted, which has the advantages of good perceptual performance and strong antinoise performance. It is regarded as the feature of spoken English pronunciation signal, so as to reduce the amount of calculation and storage of the design system.

Thirdly, the triangular filter is used to process the original oral English pronunciation signal $Q_{n}$, and the logarithmic energy expression is as follows:

$$
S(i)=\ln \left[\sum_{k=0}^{N-1}\left|P_{f}\right|^{2} S_{i}(o)\right]
$$

In formula (5), $S_{i}(o)$ represents the transfer function of the triangular filter.

3.4. Oral English Pronunciation Error Detection Modeling Module. Based on the characteristics of oral English pronunciation signal obtained by the previous oral English pronunciation preprocessing module, an error detection model of oral English pronunciation is constructed in the network environment $[12,14]$, so as to detect errors in oral
English pronunciation and prepare for automatic calibration of oral English pronunciation.

The obtained MFCC coefficients are input into the random forest model as the training dataset, and the model parameters are continuously optimized according to cross validation. At the same time, the test dataset is input into the construction model to reflect the accuracy of the construction model through the pronunciation error detection accuracy. If the pronunciation error detection accuracy is low, the model parameters need to be further optimized to make the model's oral English pronunciation error detection accuracy reach $100 \%$ as far as possible.

The framework of oral English pronunciation error detection model is shown in Figure 2.

Training the above-mentioned oral English pronunciation error detection model, due to the large amount of information contained in the corpus, there will be a problem of sparse data. Therefore, in the training process of oral English pronunciation error detection model, if you encounter an English word or phrase that has not appeared, you cannot set its occurrence probability to zero. If the probability of occurrence of an English word or phrase that has not appeared is set to zero, the probability of subsequent sentences containing new English words or phrases will be zero, and it is impossible to accurately judge its correctness and error. Therefore, during the training of oral English pronunciation error detection model, this study smoothens the oral English pronunciation data to a certain extent in the network environment to prevent the occurrence of the above phenomenon.

Through the above module design, the selection and design of effective oral English teaching platform under the network environment are realized.

\section{Realizing the Transformation of Effective Oral English Teaching Methods}

4.1. Information Technology Teaching Goal of Establishing an Effective English Teaching Model. In the network environment, the educational model of effective oral English teaching can be regarded as a cognitive model of knowledge structure, and the teaching of information technology theory course is based on the teaching model. We explore how students' learning thinking and information literacy are affected by educational methods and the impact of IT oral English teaching on students' learning thinking and information literacy. The goal of improving students' learning thinking and information literacy in the network environment is finally determined. Figure 3 shows the framework model of information technology teaching knowledge content based on the effective oral English teaching model.

As can be seen from Figure 3, the goal of the effective oral English teaching model is to highlight students' teaching thinking and information literacy. In the effective oral English teaching model, teaching thinking is the thinking in learning activities, and the students' information literacy is the thinking of information technology activities and the interaction between students and information technology. The information literacy plays a very important role in the 


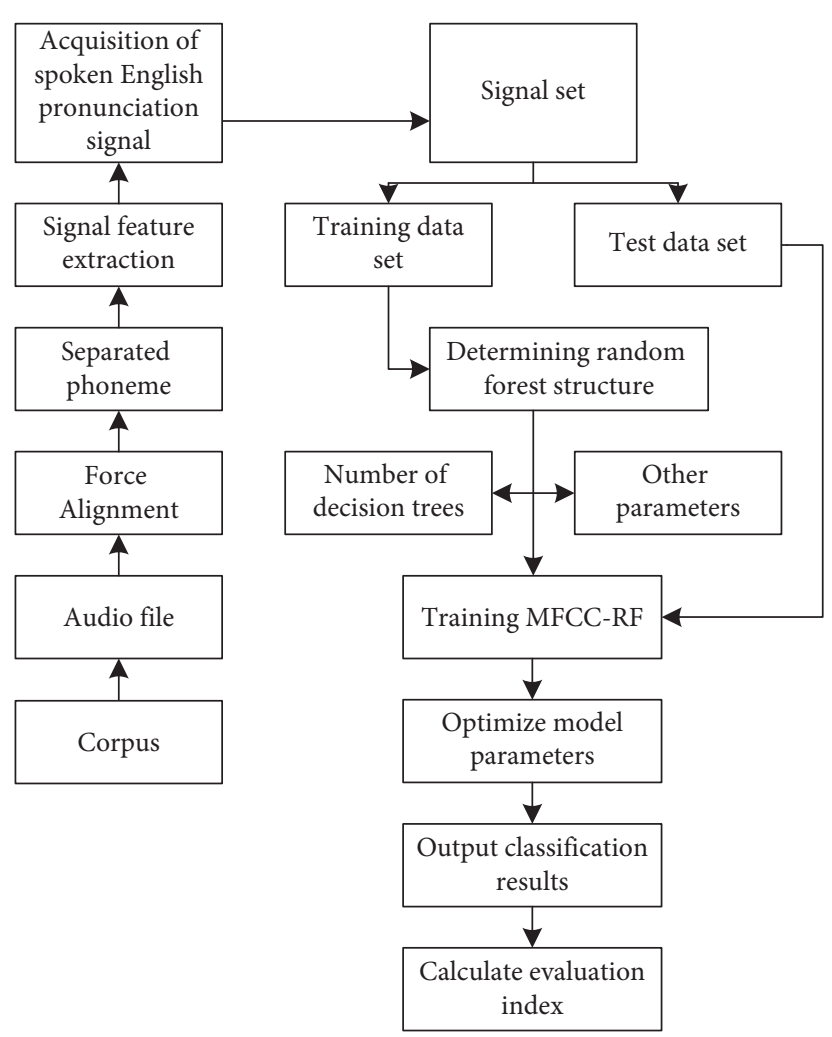

FIGURE 2: Framework of oral English pronunciation error detection model.

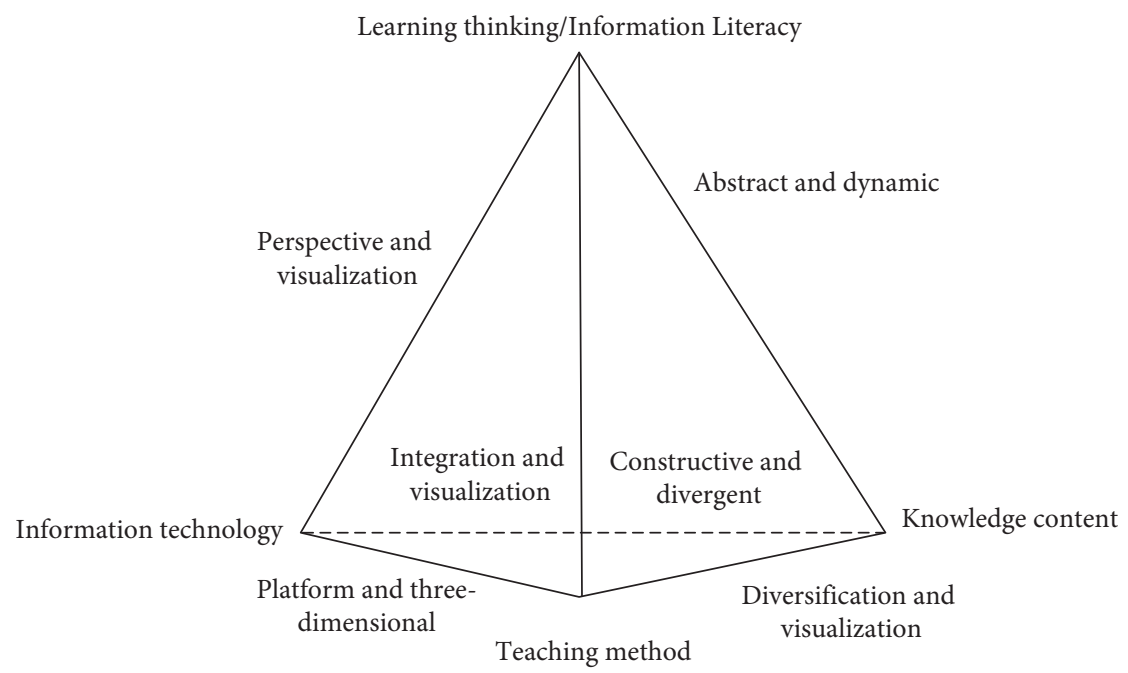

FIGURE 3: Framework model of information technology teaching knowledge content of the effective oral English teaching model.

information technology teaching activities of developing students and cultivating students' information thinking ability.

\subsection{Output Drive and Input Drive in Oral English Classroom.} In order to realize the transformation of effective oral English teaching methods and achieve the goal of oral English output, the output drive is used as the internal driving force in classroom oral practice teaching, extracurricular independent oral training, and oral output evaluation, so as to help each other, change the traditional text centered concept, and emphasize the use of oral English expression to teach students to do things in English. Output plays a dual role in the motivation and goal of language acquisition in the new hypothesis. At the same time, input is a facilitating means to help the tasks you want to output. In order to complete the current learning tasks, students should carefully study the necessary input materials and directly provide corresponding language materials and encyclopedia 
knowledge for the learning tasks. For the needs of different output tasks, different inputs should be selected. The students' oral English level is preliminarily tested, and then the students with different oral English levels are classified, and the teaching guidance and tasks are given in stages, so as to finally achieve the best oral English teaching effect. In the formal oral English teaching environment, the mark to measure the teaching effect in the output driven input facilitation theory is whether students can complete the learning task with the learned text. Therefore, the transformation of effective oral English teaching methods is the practice, detection, and reflection on students' oral English output.

4.2.1. Classroom Time Output Drive-Input Facilitation. Output driven-input driven hypothesis focuses on how to deal with the relationship between input and output in classroom teaching. The biggest difference between the traditional oral English teaching mode and the output driven input mode is reflected in the classroom setting. The traditional oral English teaching mode focuses on input and ignores output, while the output driven input in the classroom promotes the teaching mode to adapt to middle and advanced English learners and focuses on students' ability to carry out English oral output tasks, and teachers clearly take output as the driving force and adopt multifrequency practice in various ways, with the input of relevant language knowledge as the means to achieve the goal of high-quality and efficient oral English expression. Driven by the goal of oral English output activities, input, integrate, absorb, and apply the learned oral English knowledge, that is, reasonably arranging teaching activities in the classroom, taking oral English output as the purpose and direction, and arousing students' interest in learning new language knowledge. In order to complete oral English output, use relevant language materials as means to assist students to complete the output goal, improve the efficiency of classroom oral English teaching, and serve students' studies and employment. College English class hours are now reduced to a certain extent. Students' oral English needs are closely related to their studies and future careers. Students' learning characteristics change with the times and no longer adapt to the teaching mode of complete input or output. Moreover, in order to adapt to the actual situation of using oral English in the workplace, the oral English teaching mode of college students should enable students to have a practical experience of the real language. It should enable the students to learn to use it, learn to express things in English, cultivate correct outlook on life, world outlook, and values, and understand world civilization, cultural differences of various countries, and various educational philosophy ideas. It should complete the output with the help of input and through the leading role of teachers. It should design oral English tasks with practical value or potential communication value, guide students to gradually screen, integrate and use input materials, complete output tasks, and improve classroom oral English efficiency.
4.2.2. Class Time Output Drive-Input Content. Classroom teaching should consider teaching objectives, teaching contents, teaching organization, and evaluation system. These four factors are interrelated and interdependent. Teaching objectives are the key to teaching implementation, teaching content is the carrier to achieve teaching objectives, teaching organization is the means to achieve teaching objectives, and teaching evaluation is the detection of teaching objectives. Combined with the requirements of output driven input facilitation theory, output driven input facilitation in class should include the following four aspects:

(A) In terms of teaching objectives, college students' oral English classroom teaching should set realistic, clear, and measurable teaching objectives. Students are required to be able to complete communicative activities in oral expression skills. Oral English teaching needs to meet the actual needs of students. The teaching objectives should not only cultivate students' thinking ability, problem-solving ability, and sense of moral responsibility but also be clearly close to life, measurable, and evaluable, which is conducive for teachers to test the students' oral English level. When the classroom practical teaching mode is carried out, first teach the students that the unit should be carried out around the theme. It should not only express the preliminary communication of daily dialogue on the theme but also enable the students to expand their thinking, understand the social and cultural knowledge related to the theme, and enhance the logicality and innovation of students' oral English.

(B) In terms of teaching content, the new hypothesis requires that the output task needs to have potential communicative value. Input should provide a good contribution to output, and the content should provide learners with input and output through multiple channels. To have potential communicative value, it is necessary to set the output task of oral English in a communicative situation. For oral English teaching, the output task is speaking. Input and output can be allocated to each other in the following forms: listening $\longrightarrow$ reading $\longrightarrow$ speaking, listening $\longrightarrow$ translation $\longrightarrow$ speaking, reading $\longrightarrow$ listening $\longrightarrow$ writing $\longrightarrow$ speaking, rea ding $\longrightarrow$ translation $\longrightarrow$ writing $\longrightarrow$ speaking. Some links can be skipped according to the actual situation. In class, input channels, such as listening to audio, listening to video, looking at pictures, and looking at essays, can be used alternately. Among them, other output modes can be interspersed to help the smooth completion of the speech. In terms of classroom teaching content, teachers can ask questions and interact first after students' presentation, so as to prevent some students from seriously being good listeners in order to prepare their own materials or lack of concentration. Questioning interaction is a link of thinking and expression. In order to communicate, it is necessary to input $\longrightarrow$ 
integrate $\longrightarrow$ screen $\longrightarrow$ reflect $\longrightarrow$ output the information just introduced by students. This is a listening $\longrightarrow$ speaking channel. At the beginning of the main class, the teacher can provide photos or videos about the topic, attach English words or English subtitles, and then put forward topics for students to discuss. This is a channel of translation $\longrightarrow$ speaking and listening $\longrightarrow$ translation $\longrightarrow$ speaking. After reading the text, translate the key paragraphs, and then ask for imitation writing of similar topics before answering questions. This is not only a channel of reading $\longrightarrow$ translation $\longrightarrow$ writing $\longrightarrow$ speaking, but also students or teachers can analyze and judge the students' pronunciation and intonation, grammatical norms, and pragmatic appropriateness. Students can also learn from each other, learn advantages, avoid disadvantages, and improve the efficiency of oral English output.

(C) In terms of teaching organization, according to the requirements of the new hypothesis for teaching organization, college oral English teaching should ensure the following points:

(1) Class time should be reasonable. Due to the general reduction of college oral English class hours, in order to carry out teaching efficiently in a short time, it is required to distinguish primary and secondary, cherish every minute, and design all teaching links compactly.

(2) The teaching process should be carried out step by step. In order to avoid being too hasty in the teaching process, after listening to the audio or watching the video, we can directly output the final task. Teachers can select videos that match the theme. The output task is to let students input the language materials of the video and practice dialogue with their peers according to the materials given. Teachers can segment the video and let students remember the key words and then distribute text materials and practice step by step. They are not in a hurry to let students directly complete the output task, so as to make the course step by step and not stiff and no disconnection.

(3) The effectiveness of students' tasks should be checked. Usually, teachers will arrange various activities and tasks in the classroom. Some students do it in order to complete the task, and some students directly ignore the task because they think it has nothing to do with themselves. Therefore, in order to ensure the efficient completion of classroom tasks, teachers should not only check students' output results but also evaluate their output effects. Especially when individual students conduct oral English output alone, teachers should integrate themselves into the real situation, observe students' dynamics, and check students' oral English output at any time. Teachers' walking and checking teaching can not only help students benefit more from oral English in class but also improve the efficiency of classroom teaching.

(4) Classroom homework should be appropriate. It is mentioned here that appropriate, as well as group treatment, oral English homework should not be too much, because students' homework is complex one after another, quantity is not the most important, and the key depends on the results of students' completion. Appropriate, that is, the difficulty of homework, should be classified according to the groups with high and low oral English level. The lower group should mainly carry out consolidation practice outside completing the tasks in the classroom, and the higher group should carry out expansion practice.

(D) In terms of teaching evaluation, the new hypothesis requires that oral English as an output task needs to include listeners, specific evaluation criteria, and diverse ways:

(1) Oral English output needs audience, which is mostly applicable to formative evaluation. Do not turn this task into a form, so teaching is meaningless. When students do presentation and other output tasks, in order to benefit both sides, the presenter exercises the ability of oral English expression, and the audience should also be ready to be asked by the presenter or teacher at any time, record key words or important information, and find output errors or advantages. Teachers and students can correct mistakes or share oral English strategy skills in time for the speaker's oral English expression. After the students present the information, it helps students understand, internalize, and express their ideas. Both the presenter and the audience gain something in this short time.

(2) The evaluation criteria should be specific, and teachers can combine formative evaluation and summative evaluation. Give topics for students to explain their ideas in oral English. The evaluation criteria should list clear terms and send them to each student in advance, so that students can learn, understand and internalize the criteria in their usual practice, make their pronunciation and intonation natural, have something to say, correct sentence patterns and profound expression, and provide more opportunities for expression, so that students can gradually complete the output according to the evaluation criteria. Finally, the diversity of evaluation methods is reflected in the changes of oral English feedback forms, such as personal presentation, subconversation, group report, multigroup competition, and other forms, which will help improve the effect of oral English 
teaching in class, and teachers can timely record and reflect on students' feedback.

(3) The evaluation form should be intuitive. Teachers should establish a portfolio for students to complete oral English output and track and record students' performance from time to time through visible and measurable output tasks, so as to facilitate teachers to analyze the progress of students' oral English output. Evaluate the effectiveness of the teaching model, help students analyze and reflect on themselves, and improve their oral English skills.

\section{Experimental Analysis}

In order to verify the application performance of the change of effective teaching mode of spoken English under the network environment, the simulation experiment is designed on the platform of MATLAB, and the comparison items are method $s$ in [5] and [6]. The specific experimental process is as follows.

5.1. Experimental Data Preparation. This study selects Open Images dataset as the experimental dataset, which contains a large number of spoken English pronunciation data. In order to reduce the difficulty of the experiment, the sampling rate of $16 \mathrm{kHz}$ is used to randomly select 13500 types of data in the Open Images dataset. The specific experimental data information is shown in Table 3.

At the same time, the DSP chip of the design system is set as 16-bit coding, and the preweighted filtering function of spoken English pronunciation is $1-0.97 z^{-1}$. Performance parameters of sound sensor are shown in Table 4 .

\subsection{Determination of Experimental Evaluation Indicators.} In order to objectively evaluate the application performance of the design system, the evaluation indexes of the experiment are the accuracy of oral English pronunciation detection and the calibrated pronunciation quality.

Among them, the formula for calculating the error detection rate of spoken English is

$$
A_{\text {ccuracy }}=\frac{C_{R}+C_{A}}{C_{R}+F_{A}+F_{O}+C_{A}+F_{R}+C_{O}} .
$$

In (6), $C_{R}$ represents the correct number of pronunciation errors to be judged, $C_{A}$ represents the correct number of words, $F_{A}$ represents the number of mispronunciations judged to be correct, $F_{O}$ represents the type of pronunciation error and the number of errors, $F_{R}$ represents the number of correct pronunciations judged to be mispronunciations, and $C_{O}$ is the number of errors in determining the correct pronunciation type.

Calibrated pronunciation quality evaluation model is shown in Figure 4.

The formula for calculating the calibrated pronunciation quality score is
TABLE 3: Table of experimental data information.

\begin{tabular}{lcc}
\hline \multicolumn{3}{c}{ Experimental data information } \\
\hline Data type & Open testing & Close testing \\
Quantity of data & 4500 & 9000 \\
Number of speakers & 5 & 10 \\
Ratio of voice producer to male & $3: 2$ & $1: 1$ \\
Data format & \multicolumn{2}{c}{16 bits/PCM } \\
\hline
\end{tabular}

$$
S_{\text {total }}=S_{\alpha} \times 0.2+S_{\beta} \times 0.3+S_{\chi} \times 0.1+S_{\delta} \times 0.4 .
$$

In (7), $S_{\text {total }}$ represents the score result of calibrated pronunciation quality; $S_{\alpha}, S_{\beta}, S_{\chi}$, and $S_{\delta}$, respectively, represent the evaluation results of intonation, speed, rhythm, and intonation.

5.3. Analysis of Experimental Results. Based on the above experimental data and the experimental evaluation indexes, the author conducts an experiment on the change of effective teaching methods of spoken English in the network environment. The specific results are as follows.

The training time of pronunciation error detection is shown in Table 5 , and the data of pronunciation error detection rate is shown in Table 6.

According to the data comparison in Tables 5 and 6, the training time of pronunciation error detection for effective oral English teaching method designed by the methods in [5] and [6] in the network environment is shorter, and the pronunciation error detection accuracy of effective oral English teaching method is higher. The reason is that the method designed in this paper is a mobile teaching platform of case type spoken English. The overall use of $\mathrm{B} / \mathrm{S}$ architecture and client-side and serverside parallel architecture can directly break the time and space constraints of users and can be used by oral English instructors and students at any time. The whole mobile teaching platform can be divided into client and server. Users can send the instructions of each HTTP request to the data server according to the process instructions of the platform to the client. The data server will analyze the request and execute logical instructions. To some extent, it is beneficial to reduce the training time and improve the error detection rate, which indicates that the effective oral English teaching method studied in the network environment has better performance.

Using the methods in [5], in [6], and in this paper, the data of pronunciation change quality are shown in Table 7.

As shown in Table 7 , the method of change in pronunciation quality is 9.02 to 9.86 points, the method of change in pronunciation quality in [5] is 7.98 to 8.74 points, and the method of change in pronunciation quality in [6] is 7.52 to 8.12 points; the design of effective teaching method of spoken English under the network environment has a higher pronunciation quality score; the reason is that the effective teaching method of spoken English under the network environment needs a large number of data education resources transmission in the daily teaching process. Based on different data balance management algorithms, the current 
TABle 4: Performance parameter table of the sound sensor.

\begin{tabular}{lcc}
\hline Parameter & Settings & Remarks \\
\hline Sound intensity measurement & $45-120 \mathrm{~dB}$ & Gear 1 \\
Measurement waveform & $0-5 \mathrm{~V}$ & Gear 2 \\
Resolution & $1 \mathrm{~Hz}$ & - \\
Precision & $\pm 1 \%$ & - \\
Sampling frequency & 10000 times per second & Minimum value \\
Output current & $4-20 \mathrm{~mA}$ & ZS series \\
Frequency of calibration & 0 th & Software automatic zero setting \\
\hline
\end{tabular}

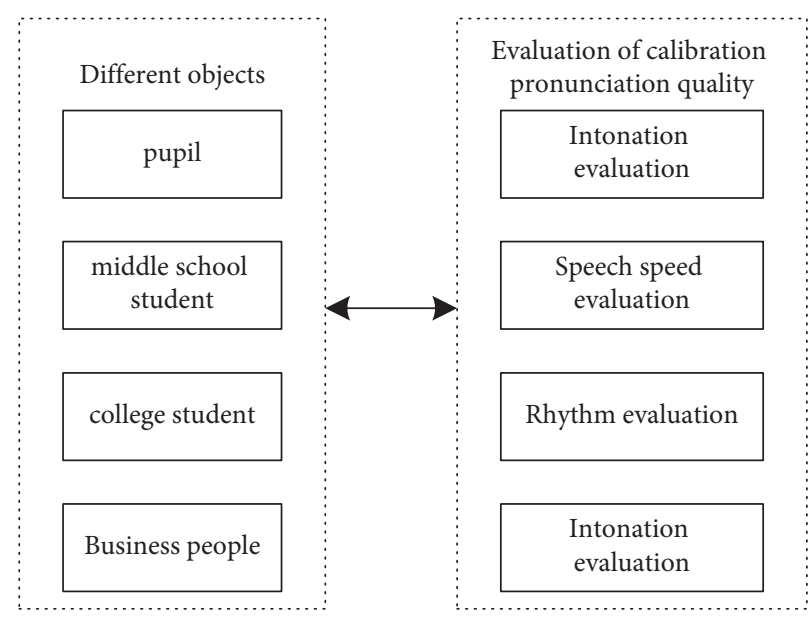

FIGURE 4: Schematic diagram of an evaluation model for calibrated pronunciation.

Table 5: Training schedule of pronunciation error detection for effective teaching methods of oral English.

\begin{tabular}{lccr}
\hline Number of test samples (piece) & \multicolumn{2}{c}{$\begin{array}{c}\text { Practice time for pronunciation error detection in effective teaching methods of oral English (s) } \\
\text { Proposed method (s) }\end{array}$} & $\begin{array}{r}\text { Adaptation theory [5] (s) } \\
\text { Autonomous ability [6] (s) }\end{array}$ \\
\hline 10 & 15.46 & 11.25 & 12.37 \\
20 & 15.00 & 11.59 & 14.25 \\
30 & 17.32 & 12.06 & 11.58 \\
40 & 17.50 & 12.36 & 10.20 \\
50 & 14.54 & 13.48 & 13.24 \\
\hline
\end{tabular}

TABLE 6: Data table of pronunciation error detection rate of effective oral English teaching methods.

\begin{tabular}{lccc}
\hline \multirow{2}{*}{$\begin{array}{l}\text { Number of test samples (piece) } \\
\text { Proposed method (\%) }\end{array}$} & \multicolumn{2}{c}{$\begin{array}{c}\text { Th) } \\
\text { Adaptation theory [5] (\%) }\end{array}$} & Autonomous ability [6] (\%) \\
\hline 10 & 96.2 & 77.50 & 85.46 \\
20 & 96.8 & 70.12 & 88.60 \\
30 & 97.1 & 69.15 & 85.00 \\
40 & 97.9 & 70.00 & 82.55 \\
50 & 98.6 & 72.12 & 87.14 \\
\hline
\end{tabular}

TABle 7: Pronunciation transition quality score data sheet.

\begin{tabular}{lccc}
\hline Numbers & Proposed method & Adaptation theory [5] & Autonomous ability [6] \\
\hline 10 & 9.02 & 7.98 & 7.52 \\
20 & 9.52 & 8.00 & 7.60 \\
30 & 9.65 & 8.45 & 6.52 \\
40 & 9.78 & 8.65 & 7.56 \\
50 & 9.86 & 8.74 & 8.12 \\
\hline
\end{tabular}


education module is changed to education global variable replacement, the platform data storage resources are saved to the maximum, the storage load is reduced, and the pronunciation quality score data can be improved to a certain extent, which shows that the study method change in pronunciation alignment is better.

\section{Conclusion and Prospects}

6.1. Conclusion. In this paper, we study the transformation of effective oral English teaching methods under the network environment. We focus on the flexibility of the current education platform and build an oral English teaching platform according to the oral English perception module. The network environment consists of the oral English perception processing module, the spoken English speech sensing selection unit, and the selection unit of oral English pronunciation processor. Under the network environment, the conversion of effective teaching methods of spoken English in this study has shorter training time, higher error detection accuracy, higher conversion pronunciation quality score, and better calibration effect, which has obvious application advantages.

\subsection{Prospects}

(1) The time limit for the implementation of oral teaching experiment will affect the reliability and validity of the experiment to a certain extent. Follow-up research can be further improved from other aspects, and the training and cultivation of oral English ability are also a long-term learning and exploration process. The validity of a certain teaching model in the short term cannot completely represent the long-term validity of this model. Therefore, if the research time can be extended in due time, the experimental results will be more convincing.

(2) To increase the sample size of the subjects, more factors shall be taken into account if the results of the experiment are to be popularized.

(3) No oral test can completely avoid the subjective factors of the raters, the oral proficiency test also has certain instability, and the test results have certain temporary characteristics. Therefore, more scientific means of oral assessment should be explored in the future to ensure higher reliability and validity.

\section{Data Availability}

The data used to support the findings of this study are available from the corresponding author upon request.

\section{References}

[1] A. Tsang, "Reconceptualizing speaking, listening, and pronunciation: glocalizing TESOL in the contexts of world englishes and English as a lingua franca," Tesol Quarterly, vol. 53, no. 2, pp. 580-588, 2019.

[2] J. Levis, "English pronunciation teaching and research: contemporary PerspectivesMarthaPennington and PamelaRogerson-revell. London, england: palgrave macmillan. Pp. Xv + 50," TESOL Quarterly, vol. 54, no. 4, pp. 1150-1152, 2020.

[3] B. Widanski, J. A. Thompson, and K. Foran-Mulcahy, "Improving students' oral scientific communication skills through targeted instruction in organic chemistry lab," Journal of Chemical Education, vol. 97, no. 10, pp. 3603-3608, 2020.

[4] E. M. Briceo, R. Mehdipanah, X. F. Gonzales, S. G. Heeringa, and L. B. Morgenstern, "Bilingualism, assessment language, and the montreal cognitive assessment in Mexican Americans," Journal of the American Geriatrics Society, vol. 7, no. 5, pp. 121-129, 2021.

[5] X. Li and L. Q. Wu, "Research on college oral English teaching from the perspective of adaptation theory," Theory and Practice of Education, vol. 40, no. 15, pp. 59-61, 2020.

[6] M. J. Xu, "Cultivation of college students' autonomous ability in oral English driven by "Internet +"," Continue Education Research, vol. 253, no. 03, pp. 106-110, 2020.

[7] W. Zhang, "On college oral English teaching in the base of virtual reality technology," in Applied Mechanics and Materialsvol. 687-691, pp. 2427-2430, Trans Tech Publications Ltd, 2014.

[8] X. Li and Y. Xie, "Application of virtual reality technology in oral English teaching for college English majors," in Journal of Physics: Conference Seriesvol. 1820, no. 1, IOP Publishing, Article ID 012148, 2021.

[9] A. Ayoub and Y. Pulijala, "The application of virtual reality and augmented reality in Oral \& Maxillofacial Surgery," BMC Oral Health, vol. 19, no. 1, pp. 238-8, 2019.

[10] C. Redmon, K. Leung, Y. Wang, B. McMurray, A. Jongman, and J. A. Sereno, "Cross-linguistic perception of clearly spoken English tense and lax vowels based on auditory, visual, and auditory-visual information," Journal of Phonetics, vol. 81, no. 7, Article ID 100980, 2020.

[11] Li. Minmin, H. Jiang, H. Yule et al., "A systematic review on botany, processing, application, phytochemistry and pharmacological action of Radix Rehmnniae," Journal of Ethnopharmacology, vol. 285, Article ID 114820, 2021.

[12] Xu Siyuan, "The efficacy of using liulishuo for spoken English ability--taking the practice of liulishuo in north China electric power university (baoding) as an example." International Education Studies, vol. 12, no. 4, pp. 244-230, 2019.

[13] Q. Xu, Q. Guo, C. X. Wang et al., "Network differentiation: a computational method of pathogenesis diagnosis in traditional Chinese medicine based on systems science," Artificial Intelligence in Medicine, vol. 118, no. 7724, Article ID 102134, 2021.

[14] X. Wang and E. Tragant, "The effect of written text on comprehension of spoken English as a foreign language: a replication study," IRAL - International Review of Applied Linguistics in Language Teaching, vol. 30, no. 10, pp. 159-164, 2019.

\section{Conflicts of Interest}

The author declares that he has no conflicts of interest. 